\title{
Information support in education process of an ontology design
}

\author{
Anastasia Malochkina \\ Department of Aircraft Design \\ Samara University \\ Samara, Russia \\ malochkina.anastasia@gmail.com
}

\author{
Nikolay Borgest \\ Department of Aircraft Design \\ Samara University \\ Samara, Russia \\ borgest@yandex.ru
}

\begin{abstract}
As the title implies the article describes information supply for both students and teachers, who is learning and teaching discipline "ontology of production sphere". The goal of this discipline is to implement ontologies creating technologies to teach students find the best solutions within aircraft designing process. Information support performs a role of communication path between tutor and student. Usage of information support will reduce time needed to fulfil routine tasks. Much attention is given to the structure of this discipline in order to provide appropriate data for support. Methods and facilities of ontology editors are described. Recommendations about information support content are given. Developed data supply is proposed to be served as an information sourse for mentioned discipline in Samara University.
\end{abstract}

Keywords - ontology; information support; education; aircraft

\section{INTRODUCTION}

The first stage of aircraft design is analysis of already existed flying machines. Previous experience helps to recognize projectable aircraft characteristics. It is abates cost, which is needed for development and producing.

Ontology (in informatics) - attempt to comprehensive and detailed formalization of a certain area of expertise with the help of conceptual schema. Ontology editors - development software specially created for designing, modification, and review of ontology [1].

In the end of course students are able to create their own ontologies to make the best choice in complicated cases.

It is possible because discipline "ontology of production sphere" gives crucial knowledge of artificial intelligence, models of data representation, and about current capacity of ontology editors.

Thus, information support is adopting as a supervision instrument for teacher and data source for student.

\section{DESCRIPTION OF AREA OF EXPERTISE}

\section{A. Course content}

Ontologies are creating in different branches of science. They can be used by experts in various spheres for shared usage and annotation of information in their area of expertise. Also, ontologies contain thesaurus needed to be used by specialists. The goal of designed thesaurus is to serve as a semantic integrative basis in creation of the ontology. Implementation of a universal controlled dictionary allows to avoid or at least heavily diminish problems, caused by definitions ambiguity [2]. Reasons for ontology creating:

- For shared usage by people and software agents each.

- For facilitation of data perception at the cost of its formalization.

- To clarify assumptions in an area of expertise.

- For review of accumulated data.

\section{B. Practice}

Practice in this discipline is fulfilled by ontology editor Magenta [3]. Goals are:

- Learning of fundamental ideas, which give characteristic of multiagent approach to software design.

- Learning of designing principles of multiagent systems creating for learning of complex systems functioning.

- Mastering of ontology tools.

- Adoption of design approach.

- Mastering of technologies for solving more complicated problems.

Fig. 1 present the result of one-way matching, received in practice. This ontology contains main characteristics of prototypes and requirements to new airplane. Fig. 1 gives information about their attitude.

Facilities of two-way matching presented in the Fig. 2. It is help to solve logistics tasks. Airplanes have a certain capacity, time and place of departure. Every cargo has its own weight and time to be in destination station. In accordance with requirements occurs distribution of cargoes.

\section{Article review and review of another ontology editors}

Special list with philosophers' works is given. Students need to choose one of them and review it. Review means: 
- Express opinion;

- Draw a conclusion;

- Explain how does this article connected with their understanding of ontology.

Review of another ontology editors necessary because it gives representation about modern facilities of ontologies creation [4].

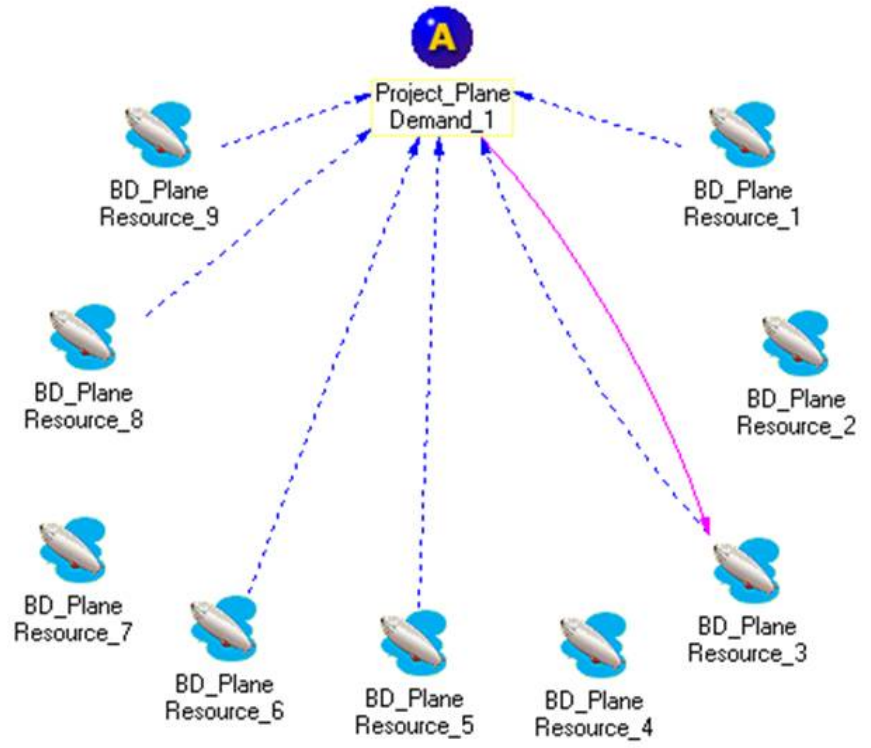

Fig. 1. One-way matching

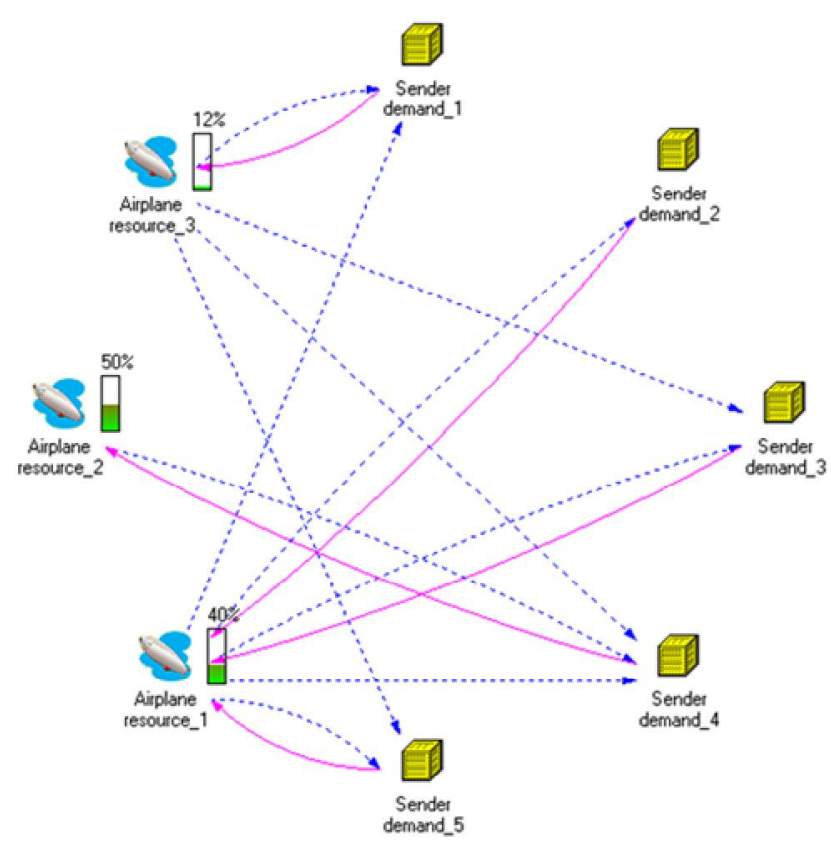

Fig. 2. Two-way matching

\section{FormalizATION OF SUBJECT AREA}

\section{A. Formalization model}

Information support is a data base consists of expert's knowledge, which play role of education goal. To adopt it to individual attributes of each student scheme in figure 3 was used.

Subject knowledge is an expert's knowledge about content and structure of teaching material. It is developed by teacher in accordance with state standard and his or her practical knowledge.

Education knowledge reflects regularities of a certain subject educational process and content subject and methodological knowledge.

Methodological knowledge is knowledge about adopting of subject knowledge.

Individual knowledge belong to student, this term used to name experts' representation about students [5].

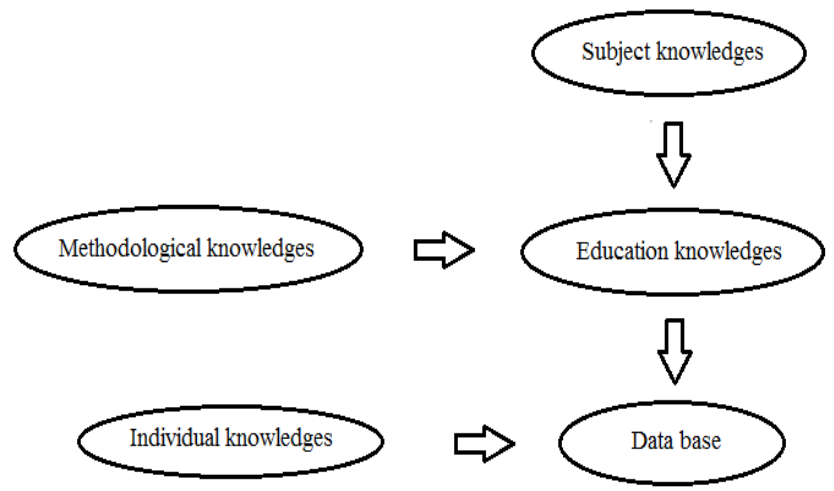

Fig. 3. Composition data base scheme of information system

\section{B. Subject data formalization}

To simplify visualization ontology of "ontology of production sphere" was created. A fragment implemented in Fluent Editor [6] shown in the Fig. 4.

\section{APPLICATION}

\section{A. Instrument description}

For application had been chosen learning management system Moodle, free and open-source software [7]. It gives wide facilities to create course.

Course consist of tests, data bases, forums with frequently asked questions, glossaries with the add opportunity.

It has a semi-automatically filled list with students' marks. Marks scale is defined for each task separately.

In accordance with Fig. 3 different types of knowledge implemented. Detailed description of introduced knowledge:

- Subject knowledge- task descriptions and comments to every segment;

- Educational knowledge - expert's experience in teaching of this course represented in course segmentation. Segments located in specially defined order; 
- Methodological knowledge - adaptation of knowledge:

first lecture in simple vocabulary with

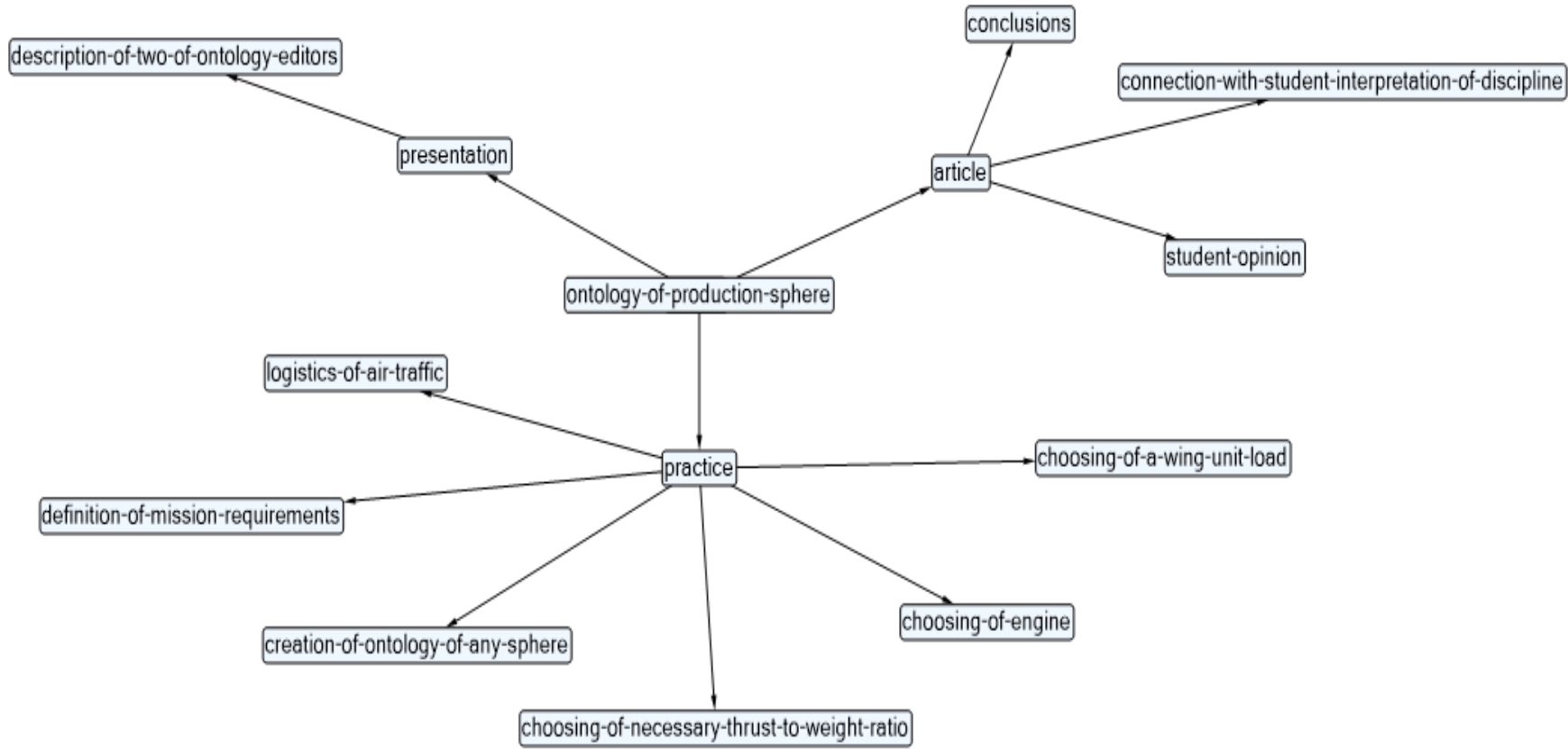

Fig. 4. Ontology for subject area

every day routine explain the most difficult terms to give approximate comprehension of subject area;

- Individual knowledge - test answer have a gradation, which may mislead in case of not good understanding. Also, checking of primary and learned knowledge provided.

Statistics of students' mistakes will be used for course optimization.

Such information support encourages preliminary selfreliant education.

Information within course segmented in a certain way. Every segment has its own deadline to stimulate students to work on time. Dates of deadlines available in block "calendar". Also notifications about deadlines switched on by default. Figure 5 is an example of segmentation.

\section{B. Novelty}

Information technology usage defines implementation of new ways for learning organization. For projecting of this course, facilities of learning discipline were used [8]. It helped to highlight the main points of subject area. Students have an access to main ontology, which was presented in figure 4. Capacity of Fluent Editor makes possible not only drafting of ontology. It can answer on some questions about information inside ontology. For it question need to be in controlled English language.
1 Practice №1

Pratice №1 "Definition of mission requirements"

Practice report №1

$\square$ Test №1

2 Practice №2

Practice №2 "Choosing of a wing unit load"

Practice report №2

母 Test №2

3 Practice №3

Practice №3 "Choosing of a necessary thrust to weight ratio"

Practice report №3

$\square$ Test №3

4 Practice №4

Practice №4 "Choosing of an engine"

Practice report №4

曰 Test №4

5 Practice №5

Practice №5 "Logisics of air transport"

Practice report №5

曰 Test №5

6 Summary work

J Definition of topic

Summary work report

7 Essay

응 Ontology library

Essay

8 Glossary

Glossary of the discipline "Ontology of production sphere"

응 References

9 Review of ontology editors

E⿱

Presentation

Fig. 5 Course interface 
Ontology is an instrument for solving several problems, which occurs in the design stage of information support for education process. It is problems such as:

- Lack of reasonable classification of knowledge about subject area and inaccuracy of terms;

- Rigidity of models for representation and review linguistically indefinite experts' knowledge about learning process.

\section{CONCLUSION}

Present time witnessed widespread of artificial intelligence, which deal with intelligent behavior, learning and adaptation in computational systems [9]. E-learning software helps to find new ways of learning process modernization. Nowadays, e-learning constantly develop to provide persistent education. Adaptation of education material in this paper was made by ontology technologies and methods. They are gives wide opportunities in every branch of science. Information support designed for course "ontology of production sphere" in Samara University only one of examples.

Successful learning of this discipline helps in another disciplines. Successful students can put into the practice formalization of engineering process, make up ontology descriptions and create their own ontologies.

Usage of ontology was helpful for exposure of conformity to e-learning process. Evaluation method of students' knowledge gives additional information about course adaption. In according to this information course can be modified to suit individual requirements of students.

Information support developing is continued. The next step is improvement of teacher and student communication within the course and transfer it to distance learning.

\section{REFERENCES}

[1] A.A. Orlova, N.M. Borgest. Text verification instruction manual using the ontologies / Proceedings of the 2016 Conference on Information Technologies in Science, Management, Social Sphere and Medicine (ITSMSSM 2016). ACSR - Advances in Comptuer Science Research. Vol. 51, 2016, pp.238-241.

[2] N.M. Borgest, M.D. Korovin. Formalization of design procedures in the engineer's educational strategy / Proceedings of the 2016 Conference on Information Technologies in Science, Management, Social Sphere and Medicine (ITSMSSM 2016). ACSR - Advances in Computer Science Research. Vol. 51, 2016, pp.524-527.

[3] MagentA. Multi-Agent Applications. Version 2/0 build 2.23. 2002. http://www.magenta-corp.com/

[4] N.M. Borgest, M.D. Korovin. Ontologies: current state, short review / Ontology of Designing. N 2(8), 2013, pp.49-55.

[5] I.Y. Denisova, P.P. Makarychev. Mathematical models of ontology knowledge base of information training system / Ontology of Designing. № 3(5). 2012, pp.62-78.

[6] FluentEditor 2014, available at: http://www.cognitum.eu/semantics /Fluent Editor/

[7] Moodle - https://moodle.org/

[8] I.Y. Denisova, P.P. Makarychev. The ontological research of e-learning process and designing of support tools / Ontology of Designing. № 4(6), 2012, pp.61-72.

[9] ONTOLOGY SUMMIT 2017 COMMUNIQU'E - AI, LEARNING, REASONING AND ONTOLOGIES / Kenneth Baclawski, Mike
Bennett, Gary Berg-Cross, Donna Fritzsche, Todd Schneider, Ravi Sharma, Ram D. Sriram and Andrea Westerninen https://s3.amazonaws.com/ontologforum/OntologySummit2017/Commu nique/OntologySummit2017Communique_v13.pdf. 